\title{
Measurement of liquid-liquid equilibria for condensate + glycol and condensate + glycol + water systems
}

Riaz, Muhammad; Kontogeorgis, Georgios; Stenby, Erling Halfdan; Yan, Wei; Haugum, Toril; Christensen, Kjersti O.; Løkken, Torbjørn V.; Solbraa, Even

Published in:

Journal of Chemical and Engineering Data

Link to article, DOI:

10.1021/je200158c

Publication date:

2011

Document Version

Publisher's PDF, also known as Version of record

Link back to DTU Orbit

Citation (APA):

Riaz, M., Kontogeorgis, G., Stenby, E. H., Yan, W., Haugum, T., Christensen, K. O., Løkken, T. V., \& Solbraa, E. (2011). Measurement of liquid-liquid equilibria for condensate + glycol and condensate + glycol + water systems. Journal of Chemical and Engineering Data, 56(12), 4342-4351. https://doi.org/10.1021/je200158c

\section{General rights}

Copyright and moral rights for the publications made accessible in the public portal are retained by the authors and/or other copyright owners and it is a condition of accessing publications that users recognise and abide by the legal requirements associated with these rights.

- Users may download and print one copy of any publication from the public portal for the purpose of private study or research.

- You may not further distribute the material or use it for any profit-making activity or commercial gain

- You may freely distribute the URL identifying the publication in the public portal 


\title{
Measurement of Liquid-Liquid Equilibria for Condensate + Glycol and Condensate + Glycol + Water Systems
}

\author{
Muhammad Riaz, ${ }^{\dagger}$ Georgios M. Kontogeorgis, ${ }_{\S}^{, \dagger}$ Erling H. Stenby, ${ }^{\ddagger}$ Wei Yan, ${ }^{\ddagger}$ Toril Haugum, ${ }^{\S}$ \\ Kjersti O. Christensen, ${ }^{\S}$ Torbjørn V. Løkken, ${ }^{\text {and Even Solbraa }}{ }^{\S}$ \\ ${ }^{\dagger}$ Department of Chemical and Biochemical Engineering, Center for Energy Resources Engineering (CERE), \\ Technical University of Denmark, DK-2800 Lyngby, Denmark \\ ${ }^{\ddagger}$ Department of Chemistry, Center for Energy Resources Engineering (CERE), Technical University of Denmark, \\ DK-2800 Lyngby, Denmark \\ $\S_{\text {S }}$ tatoil ASA, Research and Development Center, N-7005 Trondheim, Norway
}

ABSTRACT: Today's oil and gas production requires the application of various chemicals in large amounts. To evaluate the effects of those chemicals on the environment, it is of crucial importance to know how much of the chemicals are discharged via produced water and how much is dissolved in the crude oil. The ultimate objective of this work is to develop a predictive thermodynamic model for the mutual solubility of oil, water, and polar chemicals. But for the development and validation of the model, experimental data are required. This work presents new experimental liquid-liquid equilibrium (LLE) data for 1,2-ethanediol (MEG) + condensate and MEG + water + condensate systems at temperatures from (275 to 323$) \mathrm{K}$ at atmospheric pressure. The condensate used in this work is a stabilized natural gas condensate from an offshore field in the North Sea. Compositional analysis of the natural gas condensate was carried out by gas chromatography, and detailed separation of individual condensate's components has been carried out. Approximately 85 peaks eluting before nonane were identified by their retention time. Peak areas were converted to mass fraction using 1-heptene as an internal standard. The components were divided into boiling range groups from hexane to nonane. Paraffinic $(\mathrm{P})$, naphthenic $(\mathrm{N})$, and aromatic $(\mathrm{A})$ distributions were obtained for the boiling point fractions up to nonane. The average molar mass and the overall density of the condensate were measured experimentally. For the mutual solubility of MEG and condensate, approximately 72 component peaks could be detected up to nonane and many components from decane plus carbon fraction. Their solubility was quantified, and the sum was reported as solubility of condensate in MEG. A similar procedure was adopted for the MEG, condensate, and water system, but because of the presence of water, the solubility of condensate in the polar phase decreases, and some of the components were not detectable.

\section{INTRODUCTION}

Chemicals are added in almost all of the stages in oil and gas production. It is generally accepted that efficient and costeffective oil and gas production is not possible without the use of chemicals. ${ }^{1,2}$ 1,2-Ethanediol (MEG) is one of the most widely used production chemicals. It is used as a gas hydrate inhibitor to ensure reliable production and transportation. Other examples of chemicals include hydrate inhibitors (methanol, 2,2-oxidiethanol, and 2,2-ethylenedioxydiethanol), emulsion breakers [2-(2butoxyethoxy)ethyl acetate, 2-ethyl hexanol], corrosion inhibitors (sodium carbonate, sodium thiosulfate, and sodium bicarbonate), and scale inhibitors (potassium hydroxide). Chemicals added to the oil and gas value chain at different stages reach the well stream and then go to a series of separators and processing facilities. It is important to know the distribution of these chemicals in oil, water, and gas streams because it is a key to the calculation of the amounts of chemicals required for a specific facility. It is also important information to fulfill the demand from the environmental perspective to know the amount of chemicals and hydrocarbons (HC) in a processed water stream for ensuring minimal impact on marine life. Furthermore, it is important for the design and operation of separation equipment as well as to report the chemicals and water contents of fuel oil which may be crucial for downstream processing.
Table 1. Purity (in Mass Fraction, $w$ ) of the Chemicals Used in This Work

\begin{tabular}{lccl}
\multicolumn{1}{c}{ chemical } & $\begin{array}{c}\text { specific } \\
\text { purity } w \cdot 10^{2}\end{array}$ & $\begin{array}{c}\text { water } \\
\text { content } w \cdot 10^{2}\end{array}$ & \multicolumn{1}{c}{ supplier } \\
1,2-ethanediol & $>99.78$ & $<0.119$ & Acros Organics \\
dodecane & $>99.99$ & $<0.001$ & Merck \\
carbon disulfide & $>99.78$ & $<0.119$ & Acros Organics \\
\hline
\end{tabular}

The partitioning of the chemicals can either be measured experimentally or predicted using a suitable thermodynamic model. The experimental method is expensive and challenging, partly due to the difficulties involved in measurements of such low solubilities. An evidence for this is the scarcity of such experimental data (with natural gas condensate and oil) in the literature. The data are available for only few binaries and ternaries dealing with well-defined hydrocarbon, MEG, and water systems. ${ }^{5-8}$

Special Issue: Kenneth N. Marsh Festschrift

Received: February 14, 2011

Accepted: $\quad$ May 21, 2011

Published: July 08, 2011 
Table 2. Detailed Composition (in Mass Fraction, $w$, Mole Fraction, $x$ ), Molar Mass $M$, and Density $\rho$ of the Condensate

\begin{tabular}{|c|c|c|c|c|c|}
\hline & & & & $M$ & $\rho$ \\
\hline peak & component & $w \cdot 10^{2}$ & $x \cdot 10^{2}$ & $\mathrm{~g} \cdot \mathrm{mol}^{-1}$ & $\mathrm{~g} \cdot \mathrm{cm}^{-3}$ \\
\hline 1 & 2-methylpropane & 0.008 & 0.015 & 58.124 & 0.5633 \\
\hline 2 & butane & 0.287 & 0.528 & 58.124 & 0.5847 \\
\hline 3 & 2-methylbutane & 6.885 & 10.201 & 72.151 & 0.6246 \\
\hline 4 & pentane & 8.217 & 12.174 & 72.151 & 0.6309 \\
\hline 5 & 2,2-dimethylbutane & 0.408 & 0.506 & 86.178 & 0.6539 \\
\hline 6 & cyclopentane & 0.696 & 1.061 & 70.135 & 0.7502 \\
\hline 7 & 2,3-dimethylbutane & 3.316 & 4.113 & 86.178 & 0.6662 \\
\hline 8 & 3-methylpentane & 1.926 & 2.389 & 86.178 & 0.6688 \\
\hline 9 & hexane & 5.015 & 6.221 & 86.178 & 0.6638 \\
\hline 10 & 2,2-dimethylpentane & 0.164 & 0.175 & 100.205 & 0.6739 \\
\hline 11 & methylcyclopentane & 2.580 & 3.227 & 84.162 & 0.7534 \\
\hline 12 & 2,4-dimethylpentane & 0.249 & 0.266 & 100.205 & 0.6771 \\
\hline 13 & 2,2,3-trimethylbutane & 0.049 & 0.052 & 100.200 & 0.6901 \\
\hline 14 & benzene & 2.454 & 3.358 & 78.114 & 0.8842 \\
\hline 15 & 3,3-dimethylpentane & 0.088 & 0.094 & 100.205 & 0.6936 \\
\hline 16 & cyclohexane & 2.977 & 3.781 & 84.162 & 0.7831 \\
\hline 17 & 2-methylhexane & 1.463 & 1.561 & 100.205 & 0.6829 \\
\hline 18 & 2,3-dimethylpentane & 0.410 & 0.437 & 100.205 & 0.6951 \\
\hline 19 & 1,1-dimethylcyclopentane & 0.228 & 0.248 & 98.189 & 0.7590 \\
\hline 20 & 3-methylhexane & 1.535 & 1.638 & 100.205 & 0.6915 \\
\hline 21 & cis-1,3-dimethylcyclopentane & 0.487 & 0.530 & 98.189 & 0.7493 \\
\hline 22 & trans-1,3-dimethylcyclopentane & 0.446 & 0.486 & 98.189 & 0.7532 \\
\hline 23 & 3-ethylpentane & 0.082 & 0.087 & 100.200 & 0.6982 \\
\hline 24 & trans-1,2-dimethylcyclopentane & 0.801 & 0.872 & 98.189 & 0.7559 \\
\hline 25 & heptane & 3.725 & 3.974 & 100.205 & 0.6880 \\
\hline 26 & methylcyclohexane + cis-1,2-dimethylcyclopentane & 5.026 & 5.472 & 98.189 & 0.7737 \\
\hline 27 & 1,1,3-trimethylcyclopentane + 2,2-dimethylhexane & 0.270 & 0.257 & 112.216 & 0.7526 \\
\hline 28 & ethylcyclopentane & 0.295 & 0.321 & 98.189 & 0.7708 \\
\hline 29 & 2,5-dimethylhexane + 2,2,3-trimethylpentane & 0.195 & 0.182 & 114.232 & 0.7200 \\
\hline 30 & 2,4-dimethylhexane & 0.222 & 0.208 & 114.232 & 0.7045 \\
\hline 31 & 1-trans-2-cis-4-trimethylcyclopentane & 0.229 & 0.218 & 112.216 & 0.7668 \\
\hline 32 & 3,3-dimethylhexane & 0.065 & 0.061 & 114.232 & 0.7141 \\
\hline 33 & 1-trans-2-cis-3-trimethylcyclopentane & 0.226 & 0.215 & 112.216 & 0.7701 \\
\hline 34 & 2,3,4-trimethylpentane & 0.021 & 0.020 & 114.230 & 0.7191 \\
\hline 35 & methylbenzene + 2,3,3-trimethylpentane & 3.457 & 4.011 & 92.143 & 0.8714 \\
\hline 36 & 1,1,2-trimethylcyclopentane & 0.068 & 0.064 & 114.232 & 0.7660 \\
\hline 37 & 2,3-dimethylhexane & 0.142 & 0.133 & 114.232 & 0.6912 \\
\hline 38 & 3-ethyl-2-methylheptane & 0.042 & 0.039 & 114.232 & 0.7193 \\
\hline 39 & 2-methylpentane & 1.248 & 1.168 & 114.232 & 0.7019 \\
\hline 40 & 4-methylheptane +3 -ethyl-3-methylpentane & 0.395 & 0.370 & 114.232 & 0.7046 \\
\hline 41 & cis-1,3-dimethylcyclohexane & 0.901 & 0.858 & 112.216 & 0.7701 \\
\hline 42 & 3-ethylheptane + cis-2-trans-3-trimethylcyclopentane & 0.858 & 0.803 & 114.232 & 0.7099 \\
\hline 43 & 3-ethylhexane + trans-1,4-dimethylcyclohexane & 0.503 & 0.479 & 112.216 & 0.7668 \\
\hline 44 & 1,1-dimethylcyclohexane & 0.139 & 0.132 & 112.216 & 0.7809 \\
\hline 45 & 2,2,5-trimethylhexane + trans-1,3-ethylmethylcyclopentane & 0.113 & 0.094 & 128.259 & 0.7072 \\
\hline 46 & cis-1,3-ethylmethylcyclopentane & 0.109 & 0.104 & 112.216 & 0.7724 \\
\hline 47 & trans-1,2-ethylmethylcyclopentane & 0.174 & 0.166 & 112.216 & 0.7649 \\
\hline 48 & 1,1-ethylmethylcyclopentane $+2,2,4$-trimethylhexane & 0.021 & 0.018 & 128.259 & 0.7110 \\
\hline 49 & trans-1,2-dimethylcyclohexane & 0.420 & 0.400 & 112.216 & 0.7799 \\
\hline 50 & trans-1,3-dimethylcyclohexane + cis-1,4-dimethylcyclohexane & 0.261 & 0.218 & 128.259 & 0.7900 \\
\hline 51 & octane & 2.590 & 2.242 & 114.23 & 0.7065 \\
\hline 52 & 2,4,4-trimethylhexane + propylcyclopentane & 0.018 & 0.017 & 112.216 & 0.7765 \\
\hline
\end{tabular}


Table 2. Continued

\begin{tabular}{|c|c|c|c|c|c|}
\hline & & & & $M$ & $\rho$ \\
\hline peak & component & $w \cdot 10^{2}$ & $x \cdot 10^{2}$ & $\mathrm{~g} \cdot \mathrm{mol}^{-1}$ & $\mathrm{~g} \cdot \mathrm{cm}^{-3}$ \\
\hline 53 & unidentified $\mathrm{C}_{9}$ naphthene & 0.019 & 0.016 & 126.243 & 0.7900 \\
\hline 54 & unidentified $C_{9}$ naphthene & 0.017 & 0.014 & 126.243 & 0.7900 \\
\hline 55 & cis-1,2-ethylmethylcyclopentane + 2,3,5-trimethylhexane & 0.043 & 0.041 & 112.216 & 0.7900 \\
\hline 56 & 2,2-dimethylheptane & 0.123 & 0.103 & 128.259 & 0.7144 \\
\hline 57 & cis-1,2-dimethylcyclohexane & 0.028 & 0.027 & 112.216 & 0.8003 \\
\hline 58 & 2,4-dimethylheptane & 0.123 & 0.103 & 128.259 & 0.7192 \\
\hline 59 & ethylcyclohexane + propylcyclopentane & 0.879 & 0.796 & 118.000 & 0.7900 \\
\hline 60 & 4,4-dimethylheptane & 0.028 & 0.023 & 128.259 & 0.7721 \\
\hline 61 & 2,6-dimethylheptane $+\mathrm{C}_{9}$ naphthene & 0.781 & 0.651 & 128.259 & 0.7089 \\
\hline 62 & 4-ethyl-2-methylhexane & 0.053 & 0.044 & 128.259 & 0.7195 \\
\hline 63 & 2,5-dimethylheptane & 0.362 & 0.302 & 128.259 & 0.7208 \\
\hline 64 & 1,1,3-trimethylcyclohexane & 0.037 & 0.031 & 126.243 & 0.7749 \\
\hline 65 & unidentified $C_{9}$ naphthene & 0.027 & 0.023 & 126.243 & 0.7900 \\
\hline 66 & ethylbenzene & 0.519 & 0.523 & 106.168 & 0.8714 \\
\hline 67 & 3,5-dimethylheptane $+3,3$-dimethylheptane & 0.213 & 0.178 & 128.259 & 0.7262 \\
\hline 68 & unidentified $\mathrm{C}_{9}$ naphthene & 0.050 & 0.042 & 126.243 & 0.7900 \\
\hline 69 & unidentified $\mathrm{C}_{9}$ naphthene & 0.014 & 0.012 & 126.243 & 0.7900 \\
\hline 70 & 1,3-dimethylbenzene & 1.437 & 1.447 & 106.168 & 0.8642 \\
\hline 71 & 1,4-dimethylbenzene & 0.444 & 0.447 & 106.168 & 0.8611 \\
\hline 72 & 2,3-dimethylheptane & 0.074 & 0.062 & 128.259 & 0.7260 \\
\hline 73 & 3,4-dimethylheptane ${ }^{a}+$ unidentified $C_{9}$ & 0.042 & 0.035 & 128.259 & 0.7314 \\
\hline 74 & 3,4-dimethylheptane ${ }^{a}$ & 0.011 & 0.009 & 128.259 & 0.7314 \\
\hline 75 & 4-ethylheptane + unidentified $\mathrm{C}_{9}$ & 0.016 & 0.013 & 128.258 & 0.7241 \\
\hline 76 & 4-methyloctane & 0.433 & 0.361 & 128.259 & 0.7160 \\
\hline 77 & 2-methyloctane & 0.433 & 0.361 & 128.259 & 0.7095 \\
\hline 78 & 2,2,3-trimethylhexane $+\mathrm{C}_{9}$ naphthene & 0.031 & 0.026 & 128.260 & 0.7257 \\
\hline 79 & 3-ethylheptane $+\mathrm{C}_{9}$ naphthene & 0.072 & 0.060 & 128.258 & 0.7225 \\
\hline 80 & 3-methyloctane & 0.538 & 0.448 & 128.259 & 0.7170 \\
\hline 81 & 1,2-dimethylbenzene & 0.593 & 0.597 & 106.168 & 0.8844 \\
\hline 82 & unidentified $\mathrm{C}_{9}$ naphthene & 0.039 & 0.033 & 126.243 & 0.7900 \\
\hline 83 & unidentified $\mathrm{C}_{9}$ naphthene & 0.025 & 0.021 & 126.243 & 0.7900 \\
\hline 84 & unidentified $\mathrm{C}_{9}$ naphthene & 0.015 & 0.013 & 126.243 & 0.7900 \\
\hline \multirow[t]{2}{*}{85} & nonane & 2.014 & 1.679 & 128.259 & 0.7214 \\
\hline & decanes plus $\left(\mathrm{C}_{10+}\right)$ & 27.964 & 14.966 & 199.749 & 0.8364 \\
\hline
\end{tabular}

The ultimate objective of this research is to develop a predictive thermodynamic model for estimation of mutual solubility of oil, water, and polar chemicals over a wide range of conditions and with minimum input of experimental information. The model should also be able to account for the effect of a PNA (paraffinic, aromatic, and naphthenic) distribution of an oil or condensate on mutual solubility. However, for the development and validation of a thermodynamic model, experimental data are required. Those data are scarce in general, especially with gas condensate. Therefore, experimental work was carried out at Statoil Research Center in Norway to acquire the mutual solubility data for MEG + condensate and MEG + condensate + water systems.

\section{EXPERIMENTAL SECTION}

Materials. The chemicals used in this work are given in Table 1, and no further purification was carried out. The stabilized condensate was obtained from a gas field in the North Sea. Molar mass of the condensate was measured experimentally as $106.9 \mathrm{~g} \cdot \mathrm{mol}^{-1}$ using a freezing point depression method. The overall density of the condensate was also measured experimentally as $0.7385 \mathrm{~g} \cdot \mathrm{cm}^{-3}$. The detailed composition of the condensate (with density and molar mass of each component) is given in Table 2, and the details of the composition measurement method are given below.

Pure Condensate Analysis. The compositional analysis (of pure condensate) was carried out by gas chromatography (GC) with the specifications given in Table 3. ASTM standard D5134 qualitative reference naphtha standard was used to identify the components in the flame ionization detector (FID)-GC analysis. A standard temperature program ASTM D5134 was used. ${ }^{9}$ The initial column temperature was (308 \pm $0.5) \mathrm{K}$, and it was held at this level for $1800 \mathrm{~s}$. Then the temperature was ramped at the rate of $2 \mathrm{~K}$ per $60 \mathrm{~s}$ to $473 \mathrm{~K}$ and kept at this temperature for $180 \mathrm{~s}$. In the final stage, the 
Table 3. Characteristics of the Gas Chromatographs Used in This Work

\begin{tabular}{lll}
\multicolumn{1}{c}{ characteristic } & \multicolumn{1}{c}{ GC1 } \\
column name & CP-Wax 52 CB & \multicolumn{1}{c}{ GC2 } \\
column type & polar column & HP-PONA \\
column length & $30 \mathrm{~m}$ & $50 \mathrm{~m}$ \\
column internal diameter & $0.53 \mathrm{~mm}$ & $0.20 \mathrm{~mm}$ \\
column film thickness & $1 \mu \mathrm{m}$ & $0.50 \mu \mathrm{m}$ \\
injection volume & $0.20 \mathrm{~nm}$ & $0.10 \mathrm{~nm}$ \\
carrier gas & helium & helium \\
detector type & flame ionization & $\mathrm{FID}$ \\
& \multicolumn{1}{c}{ detector $(\mathrm{FID})$} & \\
rate of carrier gas & $0.075 \mu \mathrm{m}^{3} \cdot \mathrm{s}^{-1}$ & $0.015 \mu \mathrm{m}^{3} \cdot \mathrm{s}^{-1}$ \\
injection temperature & $548 \mathrm{~K}$ & $473 \mathrm{~K}$ \\
detection temperature & $533 \mathrm{~K}$ & $523 \mathrm{~K}$ \\
\hline
\end{tabular}

temperature was increased suddenly to $573 \mathrm{~K}$ within $180 \mathrm{~s}$ and kept there for $720 \mathrm{~s}$. The total time for the temperature program was $8400 \mathrm{~s}$.

For the quantification of components an internal standard 1-heptene was used. The internal standard is usually a component which is not present in an analyte sample, and its peak does not overlap with any of other component's peak. A weighed amount of the internal standard [(0.014 to 0.016$)$ mass fraction of condensate] was added in the condensate sample. Each component in the condensate appears as a peak, and its amount can be calculated using eq 1

$$
w_{i}=\frac{w_{\mathrm{IS}} \cdot A_{i} \cdot \mathrm{IRF}_{i}}{A_{\mathrm{IS}}}
$$

where $w_{i}$ is the concentration of the component $i$ (in mass fraction) in condensate sample which is required to quantify, $w_{\text {IS }}$ is the mass fraction of internal standard, $A_{\mathrm{IS}}$ is the area of the internal standard peak, $A_{i}$ is the area of component $i$, and $\mathrm{IRF}_{i}$ is the relative response factor of component $i$.

In this work a macro was used in Excel which contains the molar mass, density, and IRF of each component in the condensate. It takes the overall molar mass, density of the condensate, amount of internal standard $\left(m_{\mathrm{IS}}\right)$, and the area of its peak $\left(A_{\mathrm{IS}}\right)$ as input. It generates a report on the mass and molar composition of the condensate based on input information and peak area of each component from GC run and its IRF.

A gas chromatographic analysis of liquid sample of a condensate for the fraction $\mathrm{C}_{4}-\mathrm{C}_{9}$ (where subscript 4 and 9 represent carbon number of a hydrocarbon fraction) is given in Table 2. Approximately 85 component peaks were identified by their retention time. Peaks eluting after nonane were not indentified individually since they are beyond the scope of ASTM D5134.

Additionally above nonane some normal paraffins were also indentified. The condensed composition report of the condensate up to decane plus fraction $\left(\mathrm{C}_{10+}\right)$ is given in Table 4 . Here 2-methylpropane, butane, 2-methylbutane, and pentane are presented as individual compounds, whereas heavier hydrocarbons are grouped into carbon number fractions $\left(\mathrm{C}_{\mathrm{N}}\right)$. All of the components detected by GC between the two neighboring
Table 4. Condensed Composition (Mass Fraction, $w$, Mole Fraction, $x$ ), Molar Mass $M$, and Density $\rho$ of the Condensate

\begin{tabular}{|c|c|c|c|c|}
\hline component & $w \cdot 10^{2}$ & $x \cdot 10^{2}$ & $M / \mathrm{g} \cdot \mathrm{mol}^{-1}$ & $\rho / \mathrm{g} \cdot \mathrm{cm}^{-3}$ \\
\hline Light End Total & 15.396 & 22.917 & 71.819 & 0.6271 \\
\hline 2-methylpropane (P) & 0.008 & 0.015 & 58.121 & 0.5633 \\
\hline butane $(\mathrm{P})$ & 0.287 & 0.527 & 58.121 & 0.5847 \\
\hline 2-methylbutane (P) & 6.885 & 10.200 & 72.151 & 0.6246 \\
\hline pentane $(\mathrm{P})$ & 8.214 & 12.174 & 72.151 & 0.6309 \\
\hline Hexane Total & 11.360 & 14.289 & 84.987 & 0.6697 \\
\hline hexanes $(\mathrm{P})$ & 10.664 & 13.228 & 86.178 & 0.6651 \\
\hline hexanes $(\mathrm{N})$ & 0.696 & 1.0610 & 70.135 & 0.7502 \\
\hline Heptane Total & 17.738 & 20.837 & 91.003 & 0.7423 \\
\hline heptanes (P) & 7.765 & 8.284 & 100.205 & 0.6876 \\
\hline heptanes $(\mathrm{N})$ & 7.519 & 9.195 & 87.420 & 0.7650 \\
\hline heptanes (A) & 2.454 & 3.358 & 78.114 & 0.8842 \\
\hline Octane Total & 17.989 & 18.433 & 104.325 & 0.7655 \\
\hline octanes $(\mathrm{P})$ & 4.920 & 4.604 & 114.232 & 0.7054 \\
\hline octanes $(\mathrm{N})$ & 9.613 & 9.819 & 104.656 & 0.7655 \\
\hline octanes (A) & 3.457 & 4.011 & 92.143 & 0.8714 \\
\hline Nonane Total & 9.552 & 8.558 & 119.315 & 0.7692 \\
\hline nonanes $(\mathrm{P})$ & 4.476 & 3.731 & 128.259 & 0.7205 \\
\hline nonanes $(\mathrm{N})$ & 2.082 & 1.813 & 122.772 & 0.7546 \\
\hline nonanes (A) & 2.994 & 3.015 & 106.168 & 0.8689 \\
\hline Decane Plus & 27.964 & 14.966 & 199.749 & 0.8205 \\
\hline
\end{tabular}

normal paraffins are grouped together. They are measured and reported as a single carbon number ( $\mathrm{SCN}$ ) fraction, equal to that of the higher normal paraffin. For example all of the components eluting between hexane and heptane in a GC chromatogram are classified as $\mathrm{C}_{7}$ fraction. The carbon number of a fraction is determined according to the boiling point of the hydrocarbon components. Therefore, components may not be classified according to the number of carbon atoms in their molecules. The examples include benzene and methylbenzene. A benzene molecule contains six carbon atoms, but because the boiling point of benzene is in the $C_{7}$ cut, therefore it is classified as a $C_{7}$ component. Similarly the methylbenzene molecule has seven carbon atoms, but it is classified as the $\mathrm{C}_{8}$ component on the basis of its boiling point.

The molar mass $(M)$ and density $(\rho)$ of a carbon fraction are calculated by eqs 2 and 3 , respectively ${ }^{10}$

$$
\begin{gathered}
M_{\mathrm{C}_{\mathrm{N}}}=\frac{w_{\mathrm{C}_{\mathrm{N}}}}{\sum_{i=1}^{N_{\mathrm{C}_{\mathrm{N}}}} \frac{w_{i}}{M_{i}}} \\
\rho_{\mathrm{C}_{\mathrm{N}}}=\frac{w_{\mathrm{C}_{\mathrm{N}}}}{\sum_{i=1}^{N_{\mathrm{C}_{\mathrm{N}}}} \frac{w_{i}}{\rho_{i}}}
\end{gathered}
$$

where $w_{\mathrm{C}_{\mathrm{N}}}$ is mass fraction of components in a carbon fraction $\mathrm{C}_{\mathrm{N}}$ and $N_{\mathrm{C}_{\mathrm{N}}}$ is the number of components in the $\mathrm{C}_{\mathrm{N}}$ fraction. $w_{i}$ is the mass fraction of component $i$, and $M_{i}$ is molar mass of component $i$. 


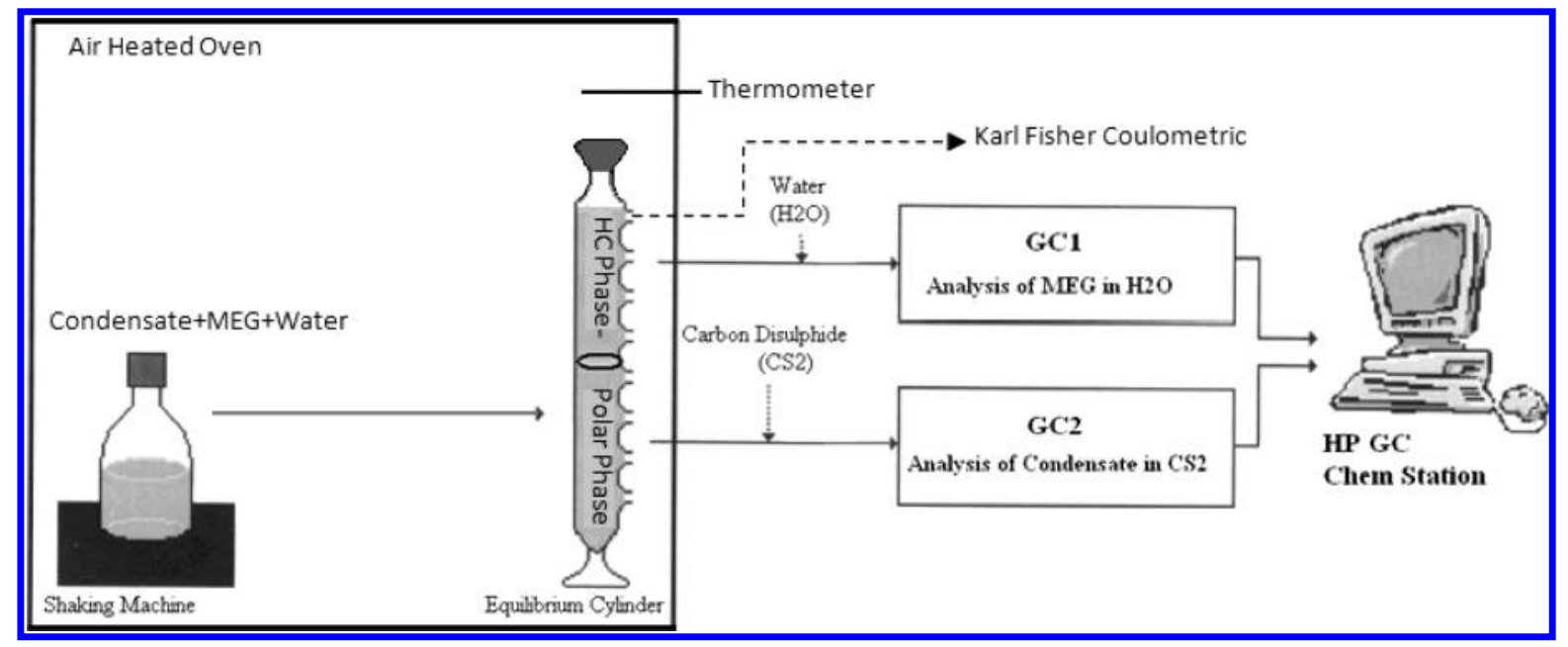

Figure 1. Sketch of the experimental setup used in this work.

The density of plus fraction $\left(\rho_{+}\right)$and molar mass of plus $\left(M_{+}\right)$ is calculated by eqs 4 and 5 , respectively ${ }^{10}$

$$
\begin{gathered}
M_{+}=\frac{M_{\mathrm{oil}} \cdot w_{+}}{1-M_{\mathrm{oil}} \sum_{i=1}^{N-1} \frac{w_{i}}{M_{i}}} \\
\rho_{+}=\frac{\rho_{\mathrm{oil}} \cdot w_{+}}{1-\rho_{\mathrm{oil}} \sum_{i=1}^{N-1} \frac{w_{i}}{\rho_{i}}}
\end{gathered}
$$

where $M_{\text {oil }}$ and $\rho_{\text {oil }}$ are respectively the average molar mass and the overall density of the oil or condensate sample and $w_{+}$is the mass fraction of the plus fraction. The densities of the components from $\mathrm{C}_{4}$ to $\mathrm{C}_{5}$ carbon fraction given in Table 4 are the pure component densities recommended by American Petroleum Institute for use in calculation of densities of oil mixtures at standard conditions.

The components in each carbon fraction can further be divided in to paraffinic $(\mathrm{P})$, naphthenic $(\mathrm{N})$, and aromatic $(\mathrm{A})$ contents known as PNA distribution of an oil or condensate. The PNA distribution in each carbon fraction is shown in Table 4. The overall PNA distribution on the basis of mass fraction shows that the condensate is paraffinic ( 0.60 mass fraction) in nature, whereas naphthenic (0.28 mass fraction) and aromatic (0.12 mass fraction) components are also present. This PNA distribution is based only on the components in $\mathrm{C}_{4}$ to $\mathrm{C}_{9}$ carbon fraction as the components above nonane cannot be identified using the GC method used in this work.

Mutual Solubility Measurements. Apparatus and Procedure. The sketch for the experimental setup used in this work is shown in Figure 1. A similar setup has been used in the previous work by Folas et al. ${ }^{5}$ and Derawi et al. ${ }^{6}$ for the experimental study of liquid-liquid equilibria of well-defined hydrocarbons and polar compounds. In this work some necessary modifications were made in the analytical methods because the hydrocarbon phase is a condensate of higher complexity as compared to the well-defined hydrocarbons. The modifications made are described in the coming sections.

Mixing and Equilibrium. MEG, condensate, and water were mixed at a fixed temperature for up to $24 \mathrm{~h}$ using a mixing machine in an air heated oven. For the MEG + condensate systems, approximately equal masses of MEG and condensate were added for mixing. In the MEG + condensate + water systems the feed mixtures contain condensate 0.50 mass fraction, and the polar compounds were also 0.50 mass fraction. The polar phase consists of MEG and water where the composition of MEG ranges from 0.40 mass fraction to 0.80 mass fraction (in polar phase) which is of interest to the industrial applications in the North Sea.

After mixing the mixture was transferred to two identical glass equilibrium cylinders, and it was kept for at least $18 \mathrm{~h}$ to attain equilibrium. The equilibrium cylinders contain holes and caps fitted with septa for sampling. Both mixing and separation were carried out in an air heated oven which was used at the temperature range from (275 to 323$) \mathrm{K}$ in this work. A DOSTMANN P500 thermometer $( \pm 0.1 \mathrm{~K})$ was used for temperature measurement.

Sampling. After equilibrium, samples from the two phases were withdrawn manually using a syringe and a needle. The needle and the syringe were preheated to avoid phase separation due to the temperature gradient. Two Agilent gas chromatographs (GCs) with different column specifications were used for composition analysis: one for the polar phase and another for the condensate phase. The characteristics of gas chromatographs used in this work are given in Table 3. The gas chromatographs are connected to a computer with the Chem Station package for data acquisition and quantification.

Polar Phase Analysis. For the polar phase analysis, hydrocarbons were extracted using the solvent extraction method. The solvent used in this work for the extraction of hydrocarbons from the polar phase is carbon disulfide $\left(\mathrm{CS}_{2}\right)$ in which hydrocarbons are soluble but MEG has negligible solubility. The amount of $\mathrm{CS}_{2}$ added for extraction was 0.30 mass fraction to 0.40 mass fraction in the condensate sample. The $\mathrm{CS}_{2}$ was mixed with the sample from the polar phase for about $900 \mathrm{~s}$ and left for the separation of the two phases. The extract phase is then analyzed on the condensate GC using the standard temperature program from ASTM standard D5134 (as for pure condensate analysis) with an internal standard 1-heptene diluted in dodecane. The internal standard was diluted to have its concentration in range of the extracted hydrocarbon components. This will result in more accurate response factors and finally more accurate quantification of HC components. The peaks of 1-heptene and dodecane 


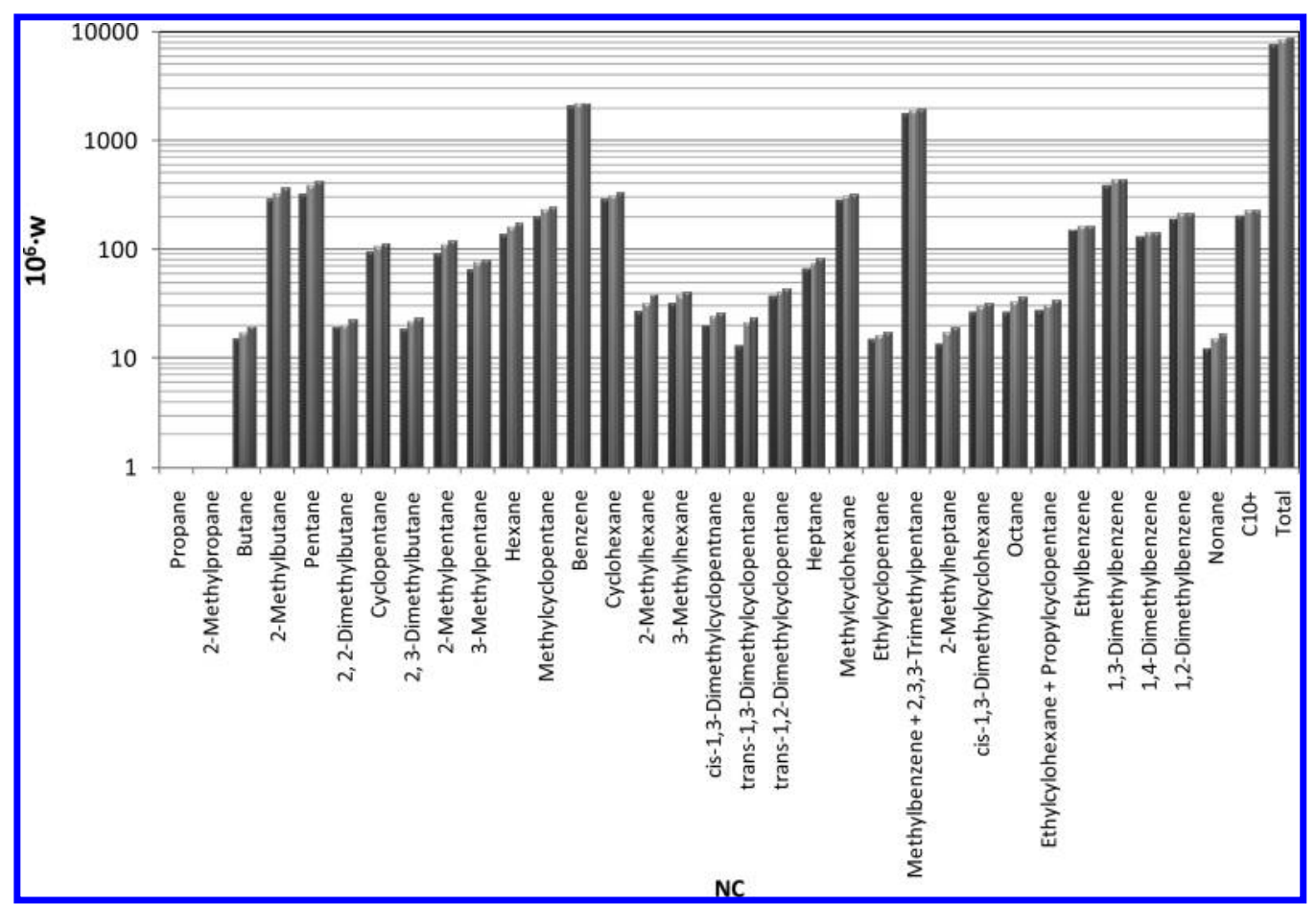

Figure 2. Solubility (in mass fraction, $w$ ) of condensate's components (NC) from various carbon fractions in pure MEG at various temperatures $(T)$ : black bar, $313.15 \mathrm{~K}$; light gray bar, $318.15 \mathrm{~K}$; dark gray bar, $323.15 \mathrm{~K}$.

should not overlap with any of the HC components peaks for safe quantification. The concentration of component $i$ in the polar phase can be calculated using eq 6 .

$$
w_{i}=A_{i} \cdot \operatorname{RF}\left[\left(\frac{m_{\mathrm{ISTD}}+m_{\text {sample }}}{m_{\text {sample }}}\right)\left(\frac{m_{\mathrm{CS}_{2}}}{m_{\text {polar }}}\right)\right]
$$

where $w_{i}$ : the mass fraction (in ppm) of HC component $i$ in polar phase; $A_{i}$ : the area of HC component $i$ obtained from the GC chromatogram; RF: the response factor of 1-heptene; $m_{\mathrm{ISTD}}$ : the mass of diluted internal standard (i.e., $m_{1 \text {-heptene }}+$ $\left.m_{1 \text {-dodecane }}\right)$ added in the sample; $m_{\text {sample }}$ the mass of sample taken from $\mathrm{CS}_{2}$ extract phase; $m_{\mathrm{CS}_{2}}$ : the mass of carbon disulfide added for extraction; $m_{\text {polar }}$ : the mass of sample taken from polar phase.

The term $\left(m_{\mathrm{ISTD}}+m_{\text {sample }}\right) / m_{\text {sample }}$ is multiplied to normalize the concentration of $\mathrm{HC}$ traces in $\mathrm{CS}_{2}$, and the term $\left(m_{\mathrm{CS}_{2}} / m_{\text {polar }}\right)$ is used to normalize the concentration of $\mathrm{HC}$ traces in the polar phase. The response factor can be calculated using eq 7

$$
\mathrm{RF}=\frac{w_{1 \text {-heptene }} \cdot 10^{6}}{A_{1 \text {-heptene }}}
$$

where $A_{1 \text {-heptene }}$ is the area of the 1 -heptene peak and $w_{1 \text {-heptene }}$ is the mass fraction of the 1-heptene in the mixture of internal standard and the sample given by eq 8

$$
w_{1 \text {-heptene }}=\frac{m_{1 \text {-heptene }}}{m_{\mathrm{ISTD}}+m_{\text {sample }}}
$$

Condensate Phase Analysis. The MEG traces from the condensate phase were extracted using water and analyzed on the glycol GC. The initial column temperature was $353 \mathrm{~K}$ and was held for $120 \mathrm{~s}$. The temperature was then increased linearly to $523 \mathrm{~K}$ in $1020 \mathrm{~s}$. The temperature $523 \mathrm{~K}$ was held for $360 \mathrm{~s}$. The total time for the temperature program is $1500 \mathrm{~s}$.

For the condensate phase analysis, the mass of water added for the extraction of MEG was approximately ( 0.30 to 0.40$)$ mass fraction of the mass of the sample. Water and the condensate were mixed for about $900 \mathrm{~s}$ to accelerate the extraction process. After mixing, some drops of the condensate remained trapped in the water phase which makes sampling for GC vial difficult. Therefore, the mixture of water and condensate was kept in an oven for about $1800 \mathrm{~s}$ at temperature about $303.15 \mathrm{~K}$. This helps the separation of both phases and condensate free sampling for GC analysis become possible. After separation, the condensate will form the upper phase, and the water containing extracted MEG will be the lower phase. The samples for GC analysis were taken from the lower phase, using a plastic syringe with a long needle. The water sample for GC analysis should not have the condensate drops because it causes a problem for the glycol GC. This is because the column temperature is too low to elute the heavy hydrocarbons present in the condensate.

The traces of MEG in condensate were quantified using a multiple point external standard method. Several external standards were made covering the expected analyte (i.e., MEG) concentration range. A linear calibration curve was constructed using the linear least-squares method. To construct the calibration curve, the standards were run before and after the actual samples. This was done to account for the drift in the signal of the GC's detector if it occurs during the GC analysis. 
The MEG is quantified automatically by HP Chem Station Package using (response factor, i.e., mass fraction/area or) eq 11 of linear calibration curve which was constructed using external standard. The mass fraction of MEG in condensate phase is calculated using eq 9 as given below

$$
w_{\mathrm{MEG}}=A_{\mathrm{MEG}} R F_{\mathrm{MEG}}\left(\frac{m_{\text {water }}}{m_{\text {condensate sample }}}\right)
$$

where $w_{\mathrm{MEG}}$ is the concentration of MEG (in mass ppm) in condensate, $A_{\mathrm{MEG}}$ is the area of the MEG peak, $\mathrm{RF}_{\mathrm{MEG}}$ is the response factor of MEG in water (mass ppm/area) given by following eq

$$
\mathrm{RF}_{\mathrm{MEG}}=\frac{w_{\mathrm{MEGstd}}}{A_{\mathrm{MEG}}}
$$

where $w_{\text {MEGstd }}$ is the known concentration of MEG in an external standard made to construct calibration curve and is given by eq 11

$$
w_{\mathrm{MEGstd}}=\left(\frac{m_{\mathrm{MEG}}}{m_{\mathrm{water}}+m_{\mathrm{MEG}}}\right) \cdot 10^{6}
$$

The term $\left(m_{\text {water }} / m_{\text {condensate sample }}\right)$ is used in eq 11 to normalize the amount of MEG in condensate sample where $m_{\text {condensate sample }}$ is the mass of condensate sample and $m_{\text {water }}$ is the mass of water added for the extraction of MEG from condensate sample.

The water contents of the condensate phase were analyzed using a Karl Fisher coulometer which provides very fast and reliable results, especially for systems with very low solubilities. In this work the apparatus Mettler Toledo DL37 coulometric titrator for determining the amount of water in the condensate phase was used. Before the analysis of the condensate sample for water content, external standards were analyzed to check the reliability of measurement. Four samples were measured for each temperature, and the mean value was reported as the condensate phase water content.

For the MEG + condensate system the average uncertainty in the measurement of solubility of MEG in condensate is $\left( \pm 16 \cdot 10^{-6}\right)$ mole fraction and for condensate in MEG is $\left( \pm 153 \cdot 10^{-6}\right)$ mole fraction. For the MEG + condensate + water system the average uncertainty for water in condensate is $\left( \pm 31 \cdot 10^{-6}\right)$ mole fraction and for MEG in condensate is $\left( \pm 7 \cdot 10^{-6}\right)$ mole fraction.

\section{EXPERIMENTAL RESULTS}

For the MEG + condensate system mutual solubilities were measured in the temperature range ( 275.15 to 323.15 ) $\mathrm{K}$. The reported solubility of condensate in MEG is the sum of solubilities of all condensate's components. About 75 components were detected from GC analysis up to nonane, and 32 of them with the highest solubilities are shown in Figure 2 with their carbon number. In this figure each column represents a condensate's component, and the height of the column represents its solubility (in mass ppm) in the polar phase. The last block of the columns represents the sum of the solubilities of all of the components for a specific temperature. It shows that in each carbon fraction the solubility of the aromatic is the highest. Therefore, aromatic components contribute approximately half of the total solubility. The solubility of MEG and condensate increases with increasing temperature, and the effect of temperature can also be seen at
Table 5. Experimental (Liquid + Liquid) Equilibrium Data for the MEG (1) + Condensate (2) System Expressed as Mole Fractions, $x$, at the Pressure of $101.3 \mathrm{kPa}$

\begin{tabular}{ccc}
$T / \mathrm{K}$ & MEG in condensate $x_{1} \cdot 10^{6}$ & condensate in MEG $x_{2} \cdot 10^{6}$ \\
275.15 & 51 & \\
283.15 & 87 & \\
303.15 & 290 & 4879 \\
308.15 & 355 & \\
313.15 & 470 & 5325 \\
318.15 & & 5860 \\
323.15 & 581 & 6084 \\
\hline
\end{tabular}

individual component level as given in Figure 2. The mutual solubility of condensate and MEG at several temperatures is given in Table 5 .

For the MEG + water + condensate systems, the mutual solubilities were measured at (303.15 and 323.15) $\mathrm{K}$ for three different polar phase compositions. In the MEG + water + condensate system the solubility of the condensate in the polar phase (MEG + water) at (323.15 and 303.15) $\mathrm{K}$ is given in Figure 3. This shows that the solubility of condensate and MEG decreases with increasing water content in polar phase. This behavior can be explained by lesser polarity of MEG than water which means increased affinity between MEG and condensate than water and condensate. The mutual solubility of MEG, water, and condensate increases with the increase in temperature. It is observed that the solubility of aromatic hydrocarbon (i.e., benzene, methylbenzene, etc.) is much higher than that of paraffinic and naphthenic. The sum of benzene and methylbenzene solubilities contributes almost the half of the total solubility of condensate in polar phase (in this specific example). This is an indication of solvation between polar chemical and aromatics. Therefore, the aromaticity or PNA distribution of an oil or condensate should be considered in modeling. The mutual solubility data for MEG + water + condensate is given in Table 6.

The experimental data were measured in mass fraction. To compare with the modeling results, it is required to convert these values into molar composition. Here we need the average molar mass of the condensate dissolved in the polar phase which is different from the molar mass weight of the original condensate in the feed. This is because the components in the original condensate will partition in different ratios between the condensate phase and the polar phase. The average molar mass $\bar{M}$ of the dissolved condensate in the polar phase was calculated by eq 12 :

$$
\bar{M}=\sum_{i=1}^{i=n} x_{i} M_{i}
$$

where $x_{i}$ is the normalized mole fraction of condensate component $i$ in polar phase and $M_{i}$ is the molar mass of component $i$.

A condensate and an oil will typically contain PNA compounds. The solubility of MEG in a specific carbon fraction (e.g., $\mathrm{C}_{7}$ ) will be the highest in the aromatic $\mathrm{HC}$ (e.g., benzene) and the lowest in the paraffinic HC (e.g., heptane). The same is also true for the solubility of HC in MEG. As a gascondensate contains both paraffinic and aromatic hydrocarbons, it 


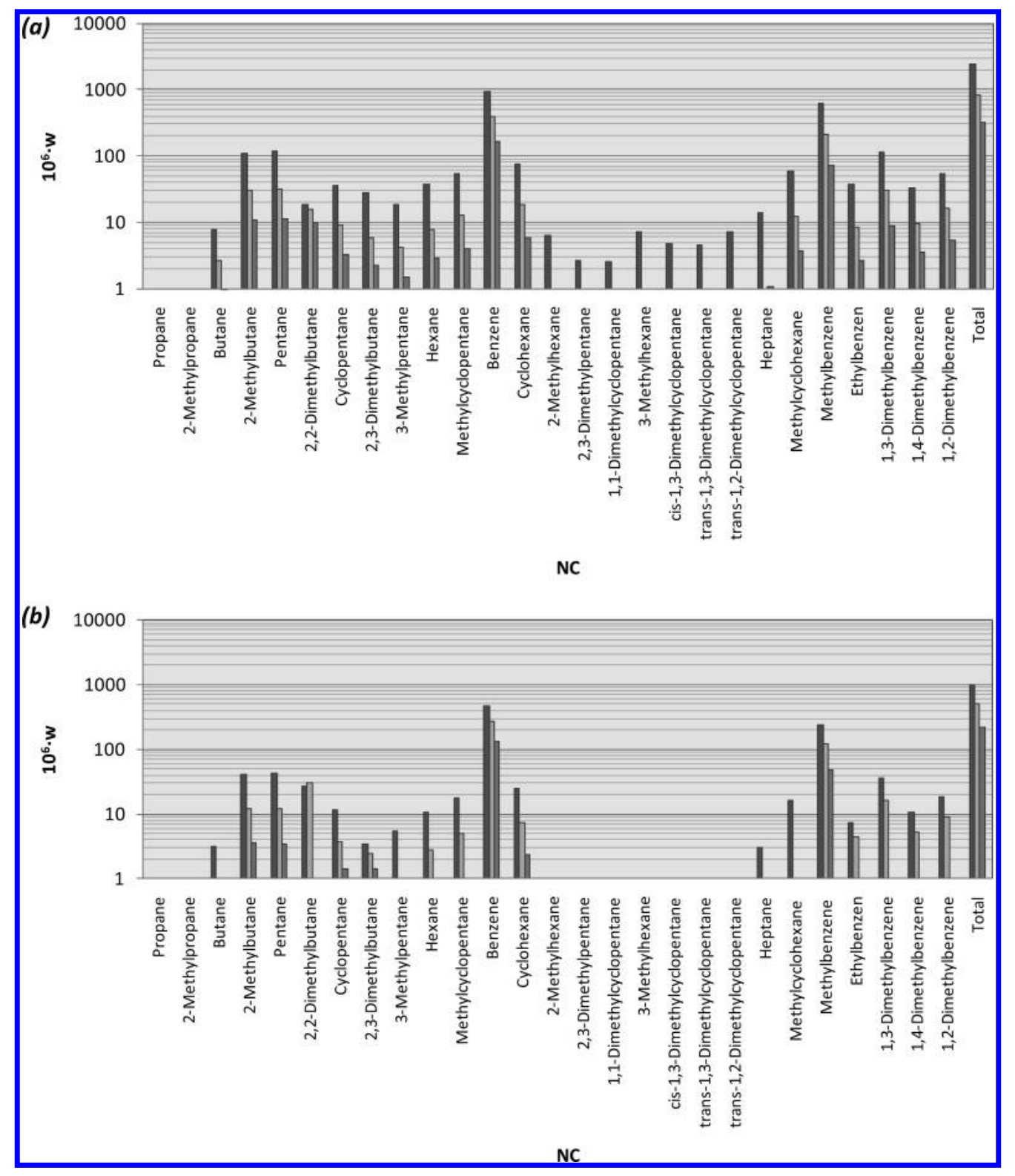

Figure 3. Solubility (in mass fraction, $w$ ) of condensate's components (NC) from various carbon fractions in polar phase (MEG + water) at temperatures (a) $323.15 \mathrm{~K}$ and (b) $303.15 \mathrm{~K}$ and MEG composition in polar phase in mass fraction black bar, 0.80; light gray bar, 0.60; dark gray bar, 0.40 .

Table 6. Experimental (Liquid + Liquid) Equilibrium Data (in Mole Fractions, $x$ ) for MEG (1) + Water (2) + Condensate (3) at Temperatures of (303.15 and 323.15) $\mathrm{K}$ and a Pressure of $101.3 \mathrm{kPa}$

\begin{tabular}{|c|c|c|c|c|c|c|c|c|}
\hline \multicolumn{3}{|c|}{ feed (mole fraction) } & \multicolumn{3}{|c|}{ polar phase (mole fraction) } & \multicolumn{3}{|c|}{ organic phase (mole fraction) } \\
\hline MEG $x_{1}$ & water $x_{2}$ & condensate $x_{3}$ & MEG $x_{1}$ & water $x_{2}$ & condensate $x_{3} \cdot 10^{6}$ & MEG $x_{1} \cdot 10^{6}$ & water $x_{2} \cdot 10^{6}$ & condensate $x_{3} \cdot 100$ \\
\hline \multicolumn{9}{|c|}{$T / \mathrm{K}=303.15$} \\
\hline 0.1312 & 0.6783 & 0.1905 & 0.1621 & 0.8378 & 67 & 36 & 806 & 99.91578 \\
\hline 0.2345 & 0.5386 & 0.2269 & 0.3033 & 0.6966 & 189 & 73 & 635 & 99.92924 \\
\hline 0.3865 & 0.3329 & 0.2805 & 0.5370 & 0.4625 & 508 & 103 & 394 & 99.95026 \\
\hline \multicolumn{9}{|c|}{$T / \mathrm{K}=323.15$} \\
\hline 0.1312 & 0.6783 & 0.1905 & 0.1621 & 0.8378 & 91 & 82 & 1309 & 99.86098 \\
\hline 0.2345 & 0.5386 & 0.2269 & 0.3032 & 0.6965 & 311 & 158 & 1119 & 99.87230 \\
\hline 0.3865 & 0.3329 & 0.2805 & 0.5366 & 0.4622 & 1181 & 328 & 784 & 99.88880 \\
\hline
\end{tabular}




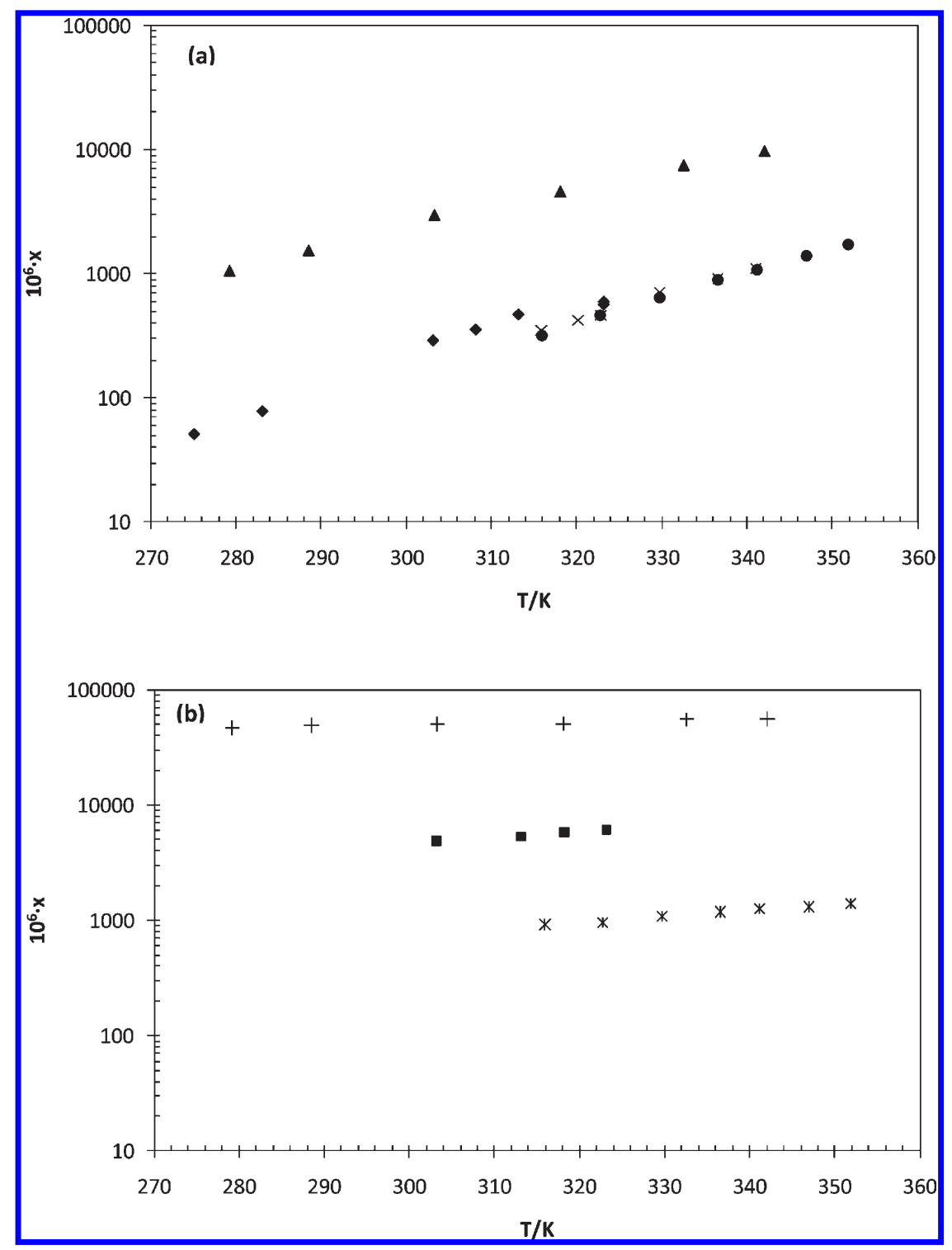

Figure 4. Comparison of the solubility (in mole fraction, $x$ ) at various temperatures, $T$, of (a) $\triangle$, MEG in heptane; $\mathbf{\Delta}, \mathrm{MEG}$ in benzene and $\boldsymbol{\bullet}, \mathrm{MEG}$ in condensate and (b) $*$, heptane in MEG; + , benzene in MEG, and $\mathbf{\square}$, condensate in MEG.

is expected that the solubility of MEG in condensate should lie between the solubility of MEG in benzene and the solubility of MEG in heptane. This is illustrated in Figure 4 where it is shown that the solubility of MEG and condensate lie between the values for the solubilities in the aromatic $C_{7}$ (benzene ${ }^{5,11}$ ) and the paraffinic $C_{7}$ (heptane). ${ }^{6}$

\section{CONCLUSIONS}

A method for the measurement of the mutual solubility of condensate, water, and MEG has been established and tested. A detailed composition of condensate is presented. The detailed composition was measured using ASTM D5134, and 85 components were detected up to nonane.

In this work new experimental LLE data for MEG + condensate and MEG + water + condensate have been presented. The condensate with the composition (mole fraction $\cdot 10^{2}$ ) 0.014 2-methylpropane, 0.491 butane, 9.49 2-methylbutane, 11.32 pentane, $13.29 \mathrm{C}_{6}, 19.37 \mathrm{C}_{7}, 17.10 \mathrm{C}_{8}, 7.78 \mathrm{C}_{9}$, and 21.16 decane plus fraction is used. The average molar mass of the condensate is $106.9 \mathrm{~g} \cdot \mathrm{mol}^{-1}$, and the overall density is $0.7385 \mathrm{~g} \cdot \mathrm{cm}^{-3}$.

In the MEG + condensate system, the mutual solubility increases with increasing temperature. The solubility of aromatic hydrocarbons is much higher than that of naphthenic and paraffinic hydrocarbons. Therefore, benzene and methylbenzene contribute a major part to the solubility of condensate in MEG. In the MEG + condensate + water system, the mutual solubility of MEG and condensate decreases with increasing water cut in feed, and some of the components disappear. The mutual solubility increases with increasing temperature, but the effect of water cut is more pronounced than that of temperature. The solubility of aromatic hydrocarbon is higher than that of naphthenic and paraffinic hydrocarbon. The aromatic components like benzene and methylbenzene contribute almost half of the total solubility of condensate in MEG. 


\section{AUTHOR INFORMATION}

\section{Corresponding Author}

*Tel.: +45 4525 2859. Fax: +45 45882258. E-mail: gk@kt.dtu.dk.

\section{Funding Sources}

The authors wish to thank all of the industrial partners in the CHIGP (Chemicals in Gas Processing) consortium (Statoil, BP International Limited, GASSCO, Mærsk Oil, DONG Energy) for financial support.

\section{ACKNOWLEDGMENT}

The authors are grateful to Statoil for the permission to publish the data.

\section{REFERENCES}

(1) Aas, N.; Knudsen, B.; Sæten, J. O.; Nordstad, E. Mass Balance of Production Chemicals, SPE 74083; Society of Petroleum Engineers: Richardson, TX, 2002.

(2) Fink, J. K. Oil Field Chemicals; Gulf Professional Pub: Amsterdam, 2003.

(3) Oliveira, M. B.; Coutinho, J. A. P.; Queimada, A. J. Mutual Solubilities of Hydrocarbons and Water with the CPA EoS. Fluid Phase Equilib. 2007, 258, 58-66.

(4) Wei, Y. S.; Sadus, R. J. Equations of State for the Calculation of Fluid-Phase Equilibria. AIChE J. 2000, 46, 169-196.

(5) Folas, G. K.; Kontogeorgis, G. M.; Michelsen, M. L.; Stenby, E. H.; Solbraa, E. Liquid-Liquid Equilibria for Binary and Ternary Systems Containing Glycols, Aromatic Hydrocarbons, and Water: Experimental Measurements and Modeling with the CPA EoS. J. Chem. Eng. Data 2006, 51, 977-983.

(6) Derawi, S. O.; Kontogeorgis, G. M.; Stenby, E. H.; Haugum, T.; Fredheim, A. O. Liquid-Liquid Equilibria for Glycols + Hydrocarbons: Data and Correlation. J. Chem. Eng. Data 2002, 47, 169-173.

(7) Razzouk, A.; Naccoul, R. A.; Mokbel, I.; Duchet-Suchaux, P.; Jose, J.; Rauzy, E.; Berro, C. Liquid-Liquid Equilibria for Monoethylene Glycol + Hexane and 2,2,4-trimethylpentane, Water + Hexane and 2,2,4-trimethylpentane, Monoethylene Glycol + Water + Hexane and Monoethylene Glycol + Water + 2,2,4-trimethylpentane in the Temperature Range between $T=283.15 \mathrm{~K}$ and $T=333.15 \mathrm{~K}$. J. Chem. Eng. Data 2010, 55, 1468-1472.

(8) Kontogeorgis, G. M.; Folas, G. K. Thermodynamic Models for Industrial Applications, from Classical and Advanced Mixing Rules to Association Theories; John Wiley \& Sons: New York, 2010.

(9) ASTM D5134-98. Standard Test Method for Detailed Analysis of Petroleum Naphthas through n-nonane by Capillary Gas Chromatography; ASTM International: West Conshohocken, PA, 2008.

(10) Pedersen, K. S.; Christensen, P. L. Phase Behavior of Petroleum Reservoir Fluids; CRC Press: Boca Raton, FL, 2007.

(11) Staveley, L. A. K.; Milward, G. L. Solutions of Alcohols in NonPolar Solvents, Some Thermodynamic Properties of Glycols in Benzene, Heptane and Cyclohexane. Part IV. J. Chem. Soc. 1957, 4369-4375. 